Dr. Jekyll or Mr. Hyde?

President Donald Trump's Personality Profile as Perceived from Different Political Viewpoints

\author{
W. Keith Campbell \\ Courtland S. Hyatt \\ University of Georgia \\ Donald R. Lynam \\ Purdue University \\ Joshua D. Miller \\ University of Georgia
}

Author Notes: Please contact W. Keith Campbell, Department of Psychology, University of Georgia, Athens, GA 30602 for additional information (email: wkeithcampbell@gmail.com). 


\begin{abstract}
The present research used an empirical, crowdsourced trait profiling approach to describe the personality of Trump that accounts for political views. Clinton $(\mathrm{N}=120)$ and Trump $(\mathrm{N}=118)$ voters rated Trump's personality on the 30 facets of the Five Factor Model. Participants also provided perceived helpfulness and harmfulness ratings of the facets before and after the election. We treated these facet level ratings as trait profiles, which were transformed into estimates of personality disorders (PDs) and complex trait-based constructs based on expert profiles. Results suggest only modest agreement between Clinton and Trump voters on Trump's personality. Clinton voters perceived much greater antagonism, lower conscientiousness, and higher levels of impairment in Trump's personality than did Trump voters who primarily perceived high levels of extraversion and emotional stability (i.e., low neuroticism). At the level of PDs and complex traits, there was some convergence with both groups seeing Trump as high in narcissism and psychopathy.
\end{abstract}




\section{Dr. Jekyll or Mr. Hyde? President Donald Trump's Personality Profile as Perceived from Different Political Viewpoints}

There is currently a great deal of debate and discussion surrounding the personality of President Donald Trump (hereafter Trump). These debates are characterized by four primary themes. The first is the issue of Trump's narcissism that has repeatedly been discussed in public forums (e.g., Campbell, 2016; Krugman, 2017; Nutt, 2016; Singer, 1997). The second is the issue of Trump's impulsivity or instability; this is not necessarily linked to narcissism, and rather has been discussed regarding hypomania and psychopathy (e.g., Brown, 2017). The third is the issue of impairment, or the perception that Trump's personality traits harm his interpersonal life and performance as president (i.e., love and work). Indeed, there have been some calls for Trump to be removed from office under the auspices of the $25^{\text {th }}$ amendment (section 4) because of this perceived impairment (e.g., Silver, 2017). Fourth, there is a debate about making psychiatric diagnoses, with psychiatrists and psychologists discouraged from diagnosing Trump from "afar" by the Goldwater rule (see Lilienfeld, Miller, \& Lynam, 2017; cf. Davis, 2017), although this has not discouraged some mental health professionals from doing so.

Of course, it may be challenging to make judgments about Trump's personality from afar, as it would be for any other public figure or group of individuals. Most researchers writing on the personality of a single eminent individual use biographical (i.e., qualitative) data; although quantitative data can be used, they are more likely to be used on a larger set of rated individuals, such a group of leaders or scientists (see Simonton, 1999, for a detailed review). Biographical data are potentially very useful for making personality ratings or clinical diagnoses, even in the absence of direct clinical or personality assessment. In the case of Trump, this biographical approach has also been used previously, notably by McAdams (2016). Several studies have used 
quantitative data to assess presidential personalities as a group, either using personality trait ratings made by actual presidential biographers (who presumably know the president's personality well; e.g., Watts et al., 2013) or by small groups of non-experts presented with biographical data (e.g., Deluga, 1997).

In the current research, we used a crowdsourced trait profiling approach to estimate Trump's personality and impairment in a way that is quantitative and can account for political differences. Our approach is grounded in a realistic assessment model (RAM; Funder, 1995). We start from the position that perceptions of personality are open to and influenced by observed behavioral, reported, or trace data; these include peer-reports, thin slices of behavior, social media activity, selected physical environment (e.g., offices), etc. We do not assume that these personality observations are necessarily fully accurate, as they can be biased by the information available to perceivers as well as the perceivers' own biases. In the present study, we attempt to investigate the degree of this potential bias through recruiting diverse observers. Specifically, we recruited individuals who reported voting for Trump as well as those who voted for Hillary Clinton (hereafter Clinton) and asked them to rate Trump's personality by collecting their perceptions of Trump's standing on general traits (i.e., Five Factor Model facets). Additionally, we assessed perceptions of the degree to which these traits caused impairment to Trump pre- and post-election.

By gathering perceptions of basic trait profiles, we can estimate the degree to which perceptions of Trump's personality comport with complex trait profiles (e.g., narcissistic personality disorder, psychopathy) without directly asking about them. We utilized a profile matching approach, such that we compared trait profiles of Trump generated by Clinton voters and Trump voters to existing expert trait profiles. This allows us to estimate the variability in 
perceived personality by voter identification, as well as the variability in perceived impairment at both the overall and facet level across time and context (i.e., pre-post election; occupational vs. interpersonal functioning).

We made two general hypotheses. First, we expected that Trump supporters would have a more favorable view of Trump's personality traits and see less impairment than would Clinton supporters (e.g., Clinton supporters would see more antagonism and disinhibition). Second, we expected that Trump's personality profile would align with narcissistic PD and related PD's (e.g., psychopathy), especially for Clinton voters.

\section{Methods}

\section{Participants and Procedure}

Participants were recruited from Amazon's Mechanical Turk. We first screened 774 American and simply asked who they had voted (if they voted) in the 2016 United States Presidential election. Of this initial sample (mean age 38.3 years [SD $=12.6$ ]; $67 \%$ female), 626 (83\%) participants reported voting in the 2016 U.S. presidential election. 316/626 (50\%) of these participants reported voting for Hillary Clinton, 208/626 (33\%) reported voting for Donald Trump, 43/626 (7\%) reported voting for Gary Johnson, and 56/626 (9\%) wrote in another candidate.

We next invited 200 Clinton voters and 200 Trump voters to participate in the trait and impairment ratings and received 120 responses from Clinton voters and 118 responses from Trump voters. Our goal was to have at least $n=100$ per condition assuming medium effect sizes, which are common in personality psychology. In the current sample, Clinton voters (mean age = $41.5, \mathrm{SD}=12.7)$ and Trump voters (mean age $=39.2, \mathrm{SD}=12.8)$ were not significantly different in age and gender composition (73\% and 64\% female, respectively). These participants provided 
ratings of Trump's personality traits and the associated helpfulness and harmfulness of each trait in multiple psychosocial domains. We paid participants $\$ .05$ for completing phase 1 and $\$ 1.50$ for phase 2; all aspects of this research were approved by the Institutional Review Board.

\section{Instruments}

FFM-Rating Form. The FFM-RF (Mullins-Sweatt, Jamerson, Samuel, Olson, \& Widiger, 2006) is a 30 item self-report measure that uses one item to assess each FFM facet. Each participant was asked to rate Trump on each of the 30 facets on a Likert scale (1-5).

Impairment Ratings. The helpfulness and harmfulness of Trump's standing on each FFM trait were measured as it pertained to pre-election Trump, post-election Trump, and Trump's personal life. For example, a sample item was “How much did Trump's anxiousness (or lack of anxiousness $\underline{\text { help }}$ him in the 2016 presidential election (i.e., before he was president)?". Items were rated on a 1 (Not at all) to 7 (Very much) scale.

\section{Results}

\section{Personality Trait Ratings}

Within Group Agreement. We first examined the within-group agreement for the Clinton and Trump voters at the overall and facet level. There was modest agreement about Trump's personality trait profile from Clinton $(I R R=.47)$ and Trump (IRR=.33) voters. At the facet level, Clinton voters also showed a pattern of generally higher agreement than Trump voters, suggesting that Clinton voters had a more unified perception of Trump than did Trump voters (Supplemental Tables 1 and 2), particularly for traits from the domain of Agreeableness. Mean Facet Ratings by Voter Identification. We next compared the mean facet level ratings of Trump separated by voter identification (see Table 1). We calculated product moment and intraclass (ICC) correlations between the FFM ratings of Trump made by Clinton voters and 
Trump voters to provide an estimate of the agreement between personality profiles of Trump. The profiles were moderately similar $\left(r=.43 ; r_{I C C}=.26\right)$. An examination of the facets show clear disagreement between Trump and Clinton voters (see Figure 1) on traits of Agreeableness and Conscientiousness such that Trump voters see Trump as much more Agreeable and Conscientious than do Clinton voters, with the smallest disagreement on the facet of Modesty, with both groups viewing Trump as very low on Modesty. The differences in perceived traits were substantial; Cohen's $d$ 's were large for 18 of 30 facets. The mean differences in descending order were for Conscientiousness (mean $d=1.46$ ), Agreeableness (mean $d=1.19$ ), Neuroticism (mean $d=.83$ ), Openness (mean $d=.68$ ), and Extraversion (mean $d=.64$ ).

Next, we examined which traits were seen as most prototypical of Trump based on voter identification (i.e., furthest away from midpoint; Table 2). In general, Clinton voters rated Trump as low in facets of Agreeableness, particularly Modesty, Tender-mindedness, Altruism, Compliance, and Trust, as well as facets of Conscientiousness, particularly Deliberation and Dutifulness. Clinton voters also rated Trump as high in Assertiveness (from Extraversion) and Anger/hostility (from Neuroticism) and low in Warmth (from Extraversion). Trump voters rated Trump as high in Assertiveness and Impulsiveness, as well as low in Modesty. However, they also rated Trump as particularly low in Depressiveness and Vulnerability (both from Neuroticism), high in Gregariousness and Activity (both from Extraversion), high in Achievement and Dutifulness (both from Conscientiousness), and high in Straightforwardness (from Agreeableness).

Profile Matching. The FFM trait profiles of Trump were matched to existing expertbased FFM profiles of personality disorders (e.g., Lynam \& Widiger, 2001). As can be seen in Figure 2, Clinton voters' average trait profile is highly similar to expert ratings for a suite of 
related constructs: narcissistic PD, psychopathy, and antisocial PD. The average Trump profile, as rated by Trump voters, also matched these constructs although at a descriptively lower level. Similarly, ratings by Clinton and Trump voters alike were highly dissimilar to expert ratings of dependent PD, avoidant PD, and schizoid PD, although the similarity was smaller for Clinton voters. The highest profile similarity for Trump voters was the expert-rated profile of successful psychopathy.

Impairment. Tables 3 and 4 provide ratings of perceptions of how helpful and harmful each trait was to Trump before and after the 2016 U.S. presidential election, as well as change scores across that time period. ${ }^{1}$ In general, Clinton voters rated Trump's traits, on average, as being moderately helpful prior to the election (mean $=4.28 ; S D=.72$ ) but generally rated these traits as less helpful following the election (mean $=2.86 ; S D=.41 ; d=2.42$ ). The size of these changes in these perceptions in descending order were: Agreeableness ( mean $=1.81 ; S D=.53$ ), Neuroticism $($ mean $=1.51 ; S D=.65)$, Openness $($ mean $=1.32 ; S D=.53)$, Extraversion $($ mean $=$ 1.28; $S D=.49$ ), and Conscientiousness (mean $=1.16 ; S D=.37$ ). Similarly, Clinton voters perceived Trump's traits as being much more hurtful, on average, after the election (mean = $4.65 ; S D=.64)$ than before the election (mean $=3.22 ; S D=.36 ; d=2.75$ ). The changes were increased perceptions of harm in traits related to Agreeableness (mean $=-1.68 ; \mathrm{SD}=.18$ ) and Neuroticism (mean $=-1.68 ; S D=.59$ ), but were also relatively large for Conscientiousness $($ mean $=-1.45 ; S D=.31)$, Openness $($ mean $=-1.26 ; S D=.33)$, and Extraversion $($ mean $=-1.11$; $S D=.22)$

Trump voters also perceived change in the degree to which Trump's traits helped him before (mean $=4.98 ; \mathrm{SD}=.60)$ vs. after $($ mean $=4.53 ; \mathrm{SD}=.58 ; d=.76)$, although the effect

\footnotetext{
${ }^{1}$ Data on perceptions of how these traits help and hurt Trump in his personal life can be found in Supplemental tables $3 \mathrm{~A}$ and $3 \mathrm{~B}$.
} 
sizes were not as large. The changes in these perceptions, aggregated at the domain level, were similar in magnitude for Agreeableness ( $m e a n=.51 ; S D=.24)$, Openness ( $m e a n=.48 ; S D=.15$ ), Neuroticism (mean $=.45 ; S D=.20$ ), Conscientiousness (mean $=.42 ; S D=.11$ ), and Extraversion (mean $=.40 S D=.27$ ). Similarly, Trump voters perceived Trump's traits as becoming only slightly more hurtful, on average, after the election $($ mean $=3.21 ; S D=.48)$ than before the election (mean $=2.88 ; S D=.44 ; d=.56$ ). Here, the biggest change was increased perceptions of harm in traits related to Neuroticism (mean $=-.46 ; \mathrm{SD}=.27$ ), with slightly smaller changes evident for Agreeableness (mean $=-.32 ; S D=.15)$, Extraversion $($ mean $=-.31 ; S D=.14)$, Openness (mean $=-.28 ; S D=.22)$, and Conscientiousness $($ mean $=-.27 ; S D=.14)$.

In general, there were small differences in perceptions of helpfulness of Trump's personality pre-election (Clinton voters: 4.28 [2.00]; Trump voters: 4.98 [1.84]; $\mathrm{d}=.36$ ); the results were similar for perceptions of harmfulness pre-election (Clinton voters: 3.22 [1.85]; Trump voters: 2.88 [1.68]; $\mathrm{d}=.19$ ). However, the sets of voters differed more substantially in their perceptions of how Trump's personality helped (Clinton voters: 2.86 [1.85]; Trump voters: 4.53 [1.44]; $\mathrm{d}=.88$ ) and harmed (Clinton voters: 4.65 [1.93]; Trump voters: 3.21 [1.82]; $\mathrm{d}=.77$ ) after the election as Clinton voters perceived these traits as being much less adaptive during the governing rather than campaigning period.

\section{Discussion}

In the current study, we estimated President Trump's personality using ratings from Trump and Clinton voters who rated Trump on the 30 facets of a popular and well-validated model of general personality traits, which allowed us to examine differences in perception of Trump's personality across political groups. We then compared the general trait profiles to configurations of traits associated with various expert personality and personality disorder 
profiles. Finally, we tested perceptions among these two voter groups of whether these traits were viewed as more helpful/hurtful before or after the election, as well as the degree of interpersonal impairment associated with each trait.

We found a modest degree of relative agreement $(r=.43)$ and more limited absolute agreement $\left(r_{I C C}=.26\right)$ between profiles for each type of voter. At the specific trait/facet level, agreement was found primarily with traits related to assertiveness, immodesty, and impulsiveness. Overall, there were dramatic differences in the personality traits perceived across the groups with 18 of 30 facets demonstrating a large difference (Cohen's $d \geq .80$ ). In fact, for several traits the group means differed by more than 1.5 standard deviations; these traits included ratings of Competence (Trump vs. Clinton voter mean ratings: 3.84 vs. 1.73), Dutifulness (Trump vs. Clinton voter mean ratings: 3.89 vs. 1.71), Straightforwardness (Trump vs. Clinton voter mean ratings: 3.97 vs. 1.83), Altruism (Trump vs. Clinton voter mean ratings: 3.05 vs. 1.39), and Self-discipline (Trump vs. Clinton voter mean ratings: 3.64 vs. 1.87). The traits where the differences were most marked all come from the broader domains of agreeableness/antagonism and conscientiousness/disinhibition. The large differences for these traits reflect the truly opposing ratings made by the two groups of voters; Clinton voters perceived Trump as being particularly low in these traits, while Trump voters perceived him to be relatively high on them.

Reflecting the modest agreement between the two trait profiles of Trump, both mean FFM profiles were associated with pathological trait profiles associated with narcissistic, antisocial, and psychopathic ("successful" and "non-successful") PDs. The degree of match with these constructs was somewhat higher for the Clinton voters, which is not surprising given their stronger endorsement of antagonistic and disinhibited traits, both of which are central to these 
PDs (e.g., Lynam \& Widiger, 2001). Previous research has examined the relations between psychopathy, narcissism, and presidential performance (Lilienfeld et al., 2012; Watts et al., 2013) finding that these traits are often trade-offs for performance. Aspects of both are linked to better performance regarding ratings of leadership, persuasiveness, communication in some domains but poorer performance regarding risk-taking, ethical lapses/impeachment resolutions. Narcissism in leadership is also linked to conflict and turbulence within an organizational system (e.g., government; Sedikides \& Campbell, 2017), and given their theoretical and empirical overlap, this link likely extends to psychopathy.

Consistent with the perceived narcissism identified by both Clinton and Trump voters, one might expect that Trump's traits would be viewed more favorably initially than over time as this is the typical perception of more narcissistic individuals in leadership positions (Campbell \& Campbell, 2009; Ong, et al., 2016). There was evidence of this trend in these data such that both sets of voters believed Trump's traits were more helpful in the campaign than they have been in governing. Although both groups of voters saw his traits as being less helpful and more impairing in his role as President vs. party nominee, there were substantial differences in size such that the "pre-post" comparisons for Clinton voters were enormous (helpful: $d=2.42$; hurtful: $d=2.75$ ) but more moderate for Trump voters (helpful: $d=.76$; hurtful: $d=.44$ ). This perceived increase in impairment is also consistent with the actual polling data, showing that after an initial brief honeymoon phase Trump's approval ratings have been trending down (FiveThirtyEight, 2017).

\section{Implications}

This research has several implications. Theoretically, consistent with the RAM model (Funder, 1995), this work shows the very different ways that individuals can perceive 
personality. What we do not know, however, is the source of these differences. Individuals could be seeing different representations of Trump (i.e., consuming news from different sources) and/or distorting the representations that they see in a way that fits their preferred image of Trump. A similar bias is found throughout the social psychological literature, whereby people gather and report information about themselves or a related group (e.g., a sports team) in a way that is self-enhancing (e.g., Hastorf \& Cantril, 1954). Likewise, in political psychology, an individual's tribal bias (e.g., Republican, Democrat) has been shown to dramatically influence their perception of political events (Bartels, 2002).

\section{Limitations}

This research also has several limitations. First, we are using personality estimates these are not expert judgments, or well-informed informant ratings (i.e., Connelly \& Ones, 2010). Our approach is based on the idea that multiple raters will converge on a reasonable profile, but it is possible that this crowd-sourced estimate is far off what experts (e.g., academic biographers of Trump) would determine. Second, the ratings were collected from MTurk, which has proven to be a reasonable source of data (e.g., Shapiro, Chandler, \& Mueller, 2013), but cannot be viewed as a random sample of American voters especially since MTurk participants tend to be relatively young (e.g., mid-30s), well-educated, and unrepresentative of the full racial, ethnic, and socioeconomic status of the American population.

Third, while we can glean from these data where sources of agreement (e.g., modesty) and disagreement (e.g., conscientiousness) lie, there is no way to determine if either set of ratings are closer to the "truth" as to the President's personality. Our raters only have access to public reports of Trump and his public actions, and thus they are rating Trump's persona, or public personality, but not necessarily his private personality. We have no way of knowing if there is a 
private Trump who remains hidden from view, and, if so, how the private Trump might differ. Fourth, these data do not speak to the mechanisms that explain these differences, but it is likely that they are due in part to the news outlets one follows (e.g., Fox News; CNN; NY Times; Breitbart), the degree to which day to day Presidential news is consumed, as well as one's trust in the news. Finally, we are using raters to estimate impairment, both as an average and as a range. Our estimates of impairment are not meant to substitute for the clinical judgment of impairment, and we are not engaging in formal clinical diagnosis.

\section{Conclusions}

Using a crowdsourced personality profiling method, the current data suggest that Trump is seen in substantially different ways by Clinton and Trump voters. Although both groups showed some convergence on traits related to narcissism (e.g., immodesty; assertiveness), the groups differed dramatically on the degree to which they viewed Trump as being interpersonally antagonistic (e.g., straightforward, altruistic, tenderminded) and disinhibited (e.g., dutiful, deliberate, self-disciplined), as well as perceptions of associated impairment. Clinton voters believed these traits helped Trump during the campaign but had come to hurt him substantially in his role as President. Trump voters believed these traits remained relatively helpful to him with a more moderate decrement from pre-election to post-election. These data point to reasons for the intense partisan divide in how Trump is viewed: similar personality-relevant information (e.g., interviews; tweets; speeches) can yield wildly different perceptions of traits. 


\section{References}

Bartels, L. M. (2002). Beyond the running tally: Partisan bias in political perceptions. Political Behavior, 24, 117-150.

Brown, J. (2017) Keith Olbermann gave Trump a psychopathy test with worrying results. Indy100. Retrieved from https://www.indy100.com/article/keith-olbermann-donald-trump-psychopath-test-resultsgq-resistance-webseries-7657321

Campbell, W. K. (2016, August 23). Is Donald Trump a Narcissist and Is He Fit for Office? Quillette. http://quillette.com/2016/08/28/is-donald-trump-a-narcissist-and-is-he-fit-for-office/

Campbell, W. K., \& Campbell, S. M. (2009). On the self-regulatory dynamics created by the peculiar benefits and costs of narcissism: A contextual reinforcement model and examination of leadership. Self and Identity, 8, 214-232.

Connelly, B. S., \& Ones, D. S. (2010). An other perspective on personality: meta-analytic integration of observers' accuracy and predictive validity. Psychological Bulletin, 136, 1092-1122.

Davis, N. J. (2017). Questioning the Goldwater Rule: Commentary on Lilienfeld, Miller, and Lynam. Perspectives on Psychological Science.

Deluga, R. J. (1997). Relationship among American presidential charismatic leadership, narcissism, and rated performance. The Leadership Quarterly, 8, 49-65.

FiveThirtyEight (2017). How popular is Donald Trump? https://projects.fivethirtyeight.com/trump-approval-ratings/ (12/16/2017). 
Funder, D. C. (1995). On the accuracy of personality judgment: a realistic approach. Psychological Review, 102, 652-670.

Hastorf, A. H., \& Cantril, H. (1954). They saw a game; a case study. The Journal of Abnormal and Social Psychology, 49, 129-134.

Krugman, P. (2017). Trump's deadly narcissism. The New York Times. Retrieved from https://www.nytimes.com/2017/09/29/opinion/trumps-deadly-narcissism.html

Lilienfeld, S. O., Miller, J. D., \& Lynam, D. R. (2017). The Goldwater Rule: Perspectives from, and implications for, psychological science. Perspectives on Psychological Science.

Lilienfeld, S. O., Waldman, I. D., Landfield, K., Watts, A. L., Rubenzer, S., \& Faschingbauer, T. R. (2012). Fearless dominance and the US presidency: implications of psychopathic personality traits for successful and unsuccessful political leadership. Journal of Personality and Social Psychology, 103, 489-505.

Lynam, D. R., \& Widiger, T. A. (2001). Using the five-factor model to represent the DSM-IV personality disorders: an expert consensus approach. Journal of Abnormal Psychology, 110, 401-412.

McAdams, D. P. (2016). The mind of Donald Trump. The Atlantic. Retreived from https://www.theatlantic.com/magazine/archive/2016/06/the-mind-of-donaldtrump/480771/

Mullins-Sweatt, S. N., Jamerson, J. E., Samuel, D. B., Olson, D. R., \& Widiger, T. A. (2006). Psychometric properties of an abbreviated instrument of the Five-Factor Model. Assessment, 13, 119-137.

Nutt, A. E. (2016). Is Donald Trump a textbook narcissist? The Washington Post. Retrieved from https://www.washingtonpost.com/news/the-fix/wp/2016/07/22/is-donald-trump-a- 
textbook-narcissist/?utm_term=.e4853d8dc903

Ong, C. W., Roberts, R., Arthur, C. A., Woodman, T., \& Akehurst, S. (2016). The leader ship is sinking: A temporal investigation of narcissistic leadership. Journal of personality, 84, 237-247.

Roberts, B. W., \& DelVecchio, W. F. (2000). The rank-order consistency of personality traits from childhood to old age: a quantitative review of longitudinal studies. Psychological Bulletin, 126, 3-25.

Sedikides, C., \& Campbell, W. K. (2017). Narcissistic force meets systemic resistance: The energy clash model. Perspectives on Psychological Science, 12, 400-421.

Shapiro, D. N., Chandler, J., \& Mueller, P. A. (2013). Using Mechanical Turk to study clinical populations. Clinical Psychological Science, 1, 213-220.

Silver, N. (2017). Will Donald Trump be impeached? Five Thirty Eight. Retrieved from https://fivethirtyeight.com/features/chance-donald-trump-impeached/

Simonton, D. K. (1999). Genius, creativity, and leadership: Historiometric inquiries. IUniverse.

Singer, M. (1997). Trump solo. The New Yorker. Retrieved from https://www.newyorker.com/magazine/1997/05/19/trump-solo

Watts, A. L., Lilienfeld, S. O., Smith, S. F., Miller, J. D., Campbell, W. K., Waldman, I. D., ... \& Faschingbauer, T. J. (2013). The double-edged sword of grandiose narcissism: Implications for successful and unsuccessful leadership among US presidents. Psychological Science, 24, 2379-2389. 
Table 1

Trump Personality Ratings by Voter Identification

\begin{tabular}{|c|c|c|c|}
\hline & $\begin{array}{c}\text { Clinton Voters } \\
\text { Mean (SD) }\end{array}$ & $\begin{array}{c}\text { Trump Voters } \\
\text { Mean (SD) }\end{array}$ & Cohen's d ${ }^{1}$ \\
\hline \multicolumn{4}{|l|}{ Neuroticism } \\
\hline Anxiousness & $3.61(1.26)$ & $2.75(1.21)$ & 0.70 \\
\hline Anger/hostility & $4.52(.77)$ & $3.38(1.07)$ & 1.22 \\
\hline Depressiveness & $2.80(1.21)$ & $1.69(1.00)$ & 1.00 \\
\hline Self-Consciousness & $1.75(1.28)$ & $2.16(1.38)$ & 0.31 \\
\hline Impulsiveness & $4.63(.85)$ & $3.88(1.11)$ & 0.76 \\
\hline Vulnerability & $3.12(1.27)$ & $1.95(1.12)$ & 0.98 \\
\hline \multicolumn{4}{|l|}{ Extraversion } \\
\hline Warmth & $1.62(.94)$ & $2.85(1.09)$ & 1.21 \\
\hline Gregariousness & $3.72(1.16)$ & $4.17(.98)$ & 0.42 \\
\hline Assertiveness & $4.64(.82)$ & $4.64(.68)$ & 0.00 \\
\hline Activity & $3.22(1.18)$ & $4.14(.93)$ & 0.87 \\
\hline Excitement-Seeking & $4.03(1.11)$ & $3.75(.93)$ & 0.27 \\
\hline Positive Emotions & $2.56(1.27)$ & $3.81(1.05)$ & 1.07 \\
\hline \multicolumn{4}{|l|}{ Openness } \\
\hline Fantasy & $3.80(1.36)$ & $2.69(1.39)$ & 0.81 \\
\hline Aesthetics & $2.72(1.41)$ & $3.32(1.23)$ & 0.45 \\
\hline Feelings & $1.72(1.00)$ & $2.96(1.27)$ & 1.08 \\
\hline Actions & $3.30(1.56)$ & $3.75(1.15)$ & 0.33 \\
\hline Ideas & $2.31(1.37)$ & $3.08(1.14)$ & 0.61 \\
\hline Values & $1.90(1.21)$ & $2.84(1.20)$ & 0.78 \\
\hline \multicolumn{4}{|l|}{ Agreeableness } \\
\hline Trust & $1.49(.89)$ & $2.61(1.09)$ & 1.13 \\
\hline Straightforwardness & $1.83(1.28)$ & $3.97(1.28)$ & 1.67 \\
\hline Altruism & $1.39(.87)$ & $3.05(1.25)$ & 1.54 \\
\hline Compliance & $1.40(.80)$ & $2.31(1.08)$ & 0.96 \\
\hline Modesty & $1.16(.53)$ & $1.77(1.11)$ & 0.70 \\
\hline Tender-mindedness & $1.36(.74)$ & $2.42(1.07)$ & 1.15 \\
\hline \multicolumn{4}{|l|}{ Conscientiousness } \\
\hline Competence & $1.73(1.00)$ & $3.84(1.22)$ & 1.89 \\
\hline Order & $2.23(1.20)$ & $3.80(1.19)$ & 1.31 \\
\hline Dutifulness & $1.71(1.16)$ & $3.89(1.16)$ & 1.88 \\
\hline Achievement & $3.16(1.41)$ & $4.30(1.14)$ & 0.89 \\
\hline Self-Discipline & $1.87(1.12)$ & $3.64(1.21)$ & 1.52 \\
\hline Deliberation & $1.45(.88)$ & $2.93(1.36)$ & 1.29 \\
\hline
\end{tabular}

Note: facet values $\geq 4$ and $\leq 1$ are bolded; ${ }^{1}$ Cohen's $d$ presented as absolute value, and large effect sizes (i.e., values $\geq .80$ ) are bolded. 
Table 2

The 10 Most Descriptive Traits of Trump by Voter Identification

\begin{tabular}{|l|l|}
\hline \multicolumn{1}{|c|}{ Clinton Voters } & \multicolumn{1}{c|}{ Trump Voters } \\
\hline Modesty (low) & Assertiveness \\
\hline Tender-mindedness (low) & Depressiveness (low) \\
\hline Assertiveness & Achievement \\
\hline Impulsiveness & Modesty (low) \\
\hline Altruism (low) & Gregariousness \\
\hline Compliance (low) & Activity \\
\hline Deliberation (low) & Vulnerability (low) \\
\hline Anger/hostility & Straightforwardness \\
\hline Trust (low) & Dutifulness \\
\hline Warmth (low) & Impulsiveness \\
\hline
\end{tabular}

Note: by most descriptive, we mean the traits that are rated as the furthest from the scalar midpoint. Traits found on the same list in same direction are bolded. 
Table 3

Ratings of Trait-Related Helpfulness/Harmfulness by Clinton Voters

\begin{tabular}{|c|c|c|c|c|c|c|}
\hline \multirow{2}{*}{ Trait } & \multicolumn{3}{|c|}{ Help } & \multicolumn{3}{|c|}{ Harm } \\
\hline & Before & After & Chg. & Before & After & Chg. \\
\hline \multicolumn{7}{|l|}{ Neuroticism } \\
\hline Anxiousness & $4.03(1.83)$ & $2.54(1.75)$ & 1.49 & $2.76(1.63)$ & $4.58(2.15)$ & -1.82 \\
\hline Anger/hostility & $5.07(1.67)$ & $2.85(1.71)$ & 2.22 & $2.96(1.66)$ & $5.20(1.80)$ & -2.24 \\
\hline Depressiveness & $3.94(2.06)$ & $3.06(1.85)$ & 0.88 & $2.34(1.51)$ & $3.25(1.91)$ & -0.91 \\
\hline Self-Consciousness & $5.08(2.05)$ & $3.22(2.15)$ & 1.86 & $2.93(1.86)$ & $5.08(1.86)$ & -2.15 \\
\hline Impulsiveness & $4.31(1.93)$ & $2.30(1.74)$ & 2.01 & $3.69(1.87)$ & $5.65(1.65)$ & -1.96 \\
\hline Vulnerability & $3.39(2.06)$ & $2.80(1.89)$ & 0.59 & $3.17(1.76)$ & $4.14(2.02)$ & -0.97 \\
\hline \multicolumn{7}{|l|}{ Extraversion } \\
\hline Warmth & $3.33(1.97)$ & $2.50(1.74)$ & 0.83 & $3.47(1.84)$ & $4.69(2.02)$ & -1.22 \\
\hline Gregariousness & $5.12(1.78)$ & $3.94(1.90)$ & 1.18 & $2.61(1.61)$ & $3.68(1.86)$ & -1.07 \\
\hline Assertiveness & $5.76(1.66)$ & $3.77(1.98)$ & 1.99 & $2.98(1.84)$ & $4.32(2.02)$ & -1.34 \\
\hline Activity & $4.30(2.12)$ & $3.38(1.89)$ & 0.92 & $2.72(1.67)$ & $3.59(1.95)$ & -0.87 \\
\hline Excitement-Seeking & $4.84(2.06)$ & $3.05(1.81)$ & 1.79 & $3.17(1.78)$ & $4.49(2.04)$ & -1.32 \\
\hline Positive Emotions & $4.07(2.06)$ & $3.09(1.93)$ & 0.98 & $3.37(1.91)$ & $4.20(1.92)$ & -0.83 \\
\hline \multicolumn{7}{|l|}{ Openness } \\
\hline Fantasy & $4.87(2.04)$ & $2.93(1.79)$ & 1.94 & $3.08(1.83)$ & $4.51(2.07)$ & -1.43 \\
\hline Aesthetics & $3.26(1.83)$ & $2.76(1.76)$ & 0.50 & $2.81(1.83)$ & $3.41(1.85)$ & -0.60 \\
\hline Feelings & $3.40(2.05)$ & $2.52(1.69)$ & 0.88 & $3.62(2.06)$ & $4.87(1.85)$ & -1.25 \\
\hline Actions & $4.87(1.85)$ & $3.23(1.72)$ & 1.64 & $3.25(1.72)$ & $4.72(1.98)$ & -1.47 \\
\hline Ideas & $4.00(1.99)$ & $2.58(1.80)$ & 1.42 & $3.50(1.89)$ & $4.96(1.87)$ & -1.46 \\
\hline Values & $4.55(1.95)$ & $3.00(1.88)$ & 1.55 & $3.45(1.80)$ & $4.82(1.88)$ & -1.37 \\
\hline \multicolumn{7}{|l|}{ Agreeableness } \\
\hline Trust & $4.12(2.15)$ & $2.66(1.82)$ & 1.46 & $3.61(2.00)$ & $5.31(1.72)$ & -1.70 \\
\hline Straightforwardness & $4.77(2.11)$ & $2.89(1.93)$ & 1.88 & $3.38(1.87)$ & $5.10(1.93)$ & -1.72 \\
\hline Altruism & $3.48(2.23)$ & $2.45(1.84)$ & 1.03 & $3.53(1.84)$ & $4.90(2.04)$ & -1.37 \\
\hline Compliance & $5.04(1.99)$ & $2.83(1.94)$ & 2.21 & $3.42(1.94)$ & $5.22(1.73)$ & -1.80 \\
\hline Modesty & $5.35(1.95)$ & $2.84(1.93)$ & 2.51 & $3.23(2.08)$ & $5.12(1.87)$ & -1.89 \\
\hline Tender-mindedness & $4.46(2.23)$ & $2.71(1.81)$ & 1.75 & $3.29(2.00)$ & $4.91(1.97)$ & -1.62 \\
\hline \multicolumn{7}{|l|}{ Conscientiousness } \\
\hline Competence & $3.28(2.09)$ & $2.33(1.87)$ & 0.95 & $3.76(2.00)$ & $5.58(1.83)$ & -1.82 \\
\hline Order & $3.27(2.08)$ & $2.69(1.90)$ & 0.58 & $3.01(1.78)$ & $4.30(2.14)$ & -1.29 \\
\hline Dutifulness & $3.60(2.20)$ & $2.45(1.92)$ & 1.15 & $3.51(2.03)$ & $4.92(2.08)$ & -1.41 \\
\hline Achievement & $4.90(2.07)$ & $3.54(2.08)$ & 1.36 & $2.72(1.86)$ & $3.79(2.09)$ & -1.07 \\
\hline Self-Discipline & $3.82(2.04)$ & $2.60(1.79)$ & 1.22 & $3.45(1.99)$ & $4.73(2.06)$ & -1.28 \\
\hline Deliberation & $4.09(2.01)$ & $2.41(1.74)$ & 1.68 & $3.68(1.95)$ & $5.51(1.87)$ & -1.83 \\
\hline Average across all traits & $4.28(2.00)$ & $2.86(1.85)$ & 1.16 & $3.22(1.85)$ & $4.65(1.93)$ & -1.45 \\
\hline
\end{tabular}

Note. Chg $=$ Change in rating from before to after the election. 
Table 4

Ratings of Trait-Related Helpfulness/Harmfulness by Trump Voters

\begin{tabular}{|c|c|c|c|c|c|c|}
\hline \multirow[b]{2}{*}{ Trait } & \multicolumn{3}{|c|}{ Help } & \multicolumn{3}{|c|}{ Harm } \\
\hline & Before & After & Chg. & Before & After & Chg. \\
\hline \multicolumn{7}{|l|}{ Neuroticism } \\
\hline Anxiousness & $4.34(1.82)$ & $4.00(1.88)$ & 0.34 & $2.71(1.59)$ & $3.37(1.79)$ & -0.66 \\
\hline Anger/hostility & $4.48(1.88)$ & $3.95(1.89)$ & 0.53 & $3.14(1.52)$ & $3.79(1.76)$ & -0.65 \\
\hline Depressiveness & $4.89(2.10)$ & $4.66(2.13)$ & 0.23 & $2.01(1.57)$ & $2.06(1.56)$ & -0.05 \\
\hline Self-Consciousness & $5.10(1.83)$ & $4.60(1.96)$ & 0.50 & $2.93(1.61)$ & $3.17(1.78)$ & -0.24 \\
\hline Impulsiveness & $4.65(1.85)$ & $3.86(1.89)$ & 0.79 & $3.32(1.11)$ & $4.03(1.91)$ & -0.71 \\
\hline Vulnerability & $4.96(2.07)$ & $4.66(2.01)$ & 0.30 & $2.25(1.61)$ & $2.71(1.67)$ & -0.46 \\
\hline \multicolumn{7}{|l|}{ Extraversion } \\
\hline Warmth & 4.06 & $4.04(2.02)$ & 0.02 & 3.35( & $3.78(1.89)$ & -0.43 \\
\hline Gregarious & $5.52(1.78)$ & $4.99(1.85)$ & 0.53 & $2.39(1.51)$ & $2.67(1.67)$ & -0.28 \\
\hline Assertivent & $6.14(1$ & $5.45(1.63)$ & 0.69 & $2.72(1.69)$ & 3.22 & -0.50 \\
\hline Activity & 5.61( & 5.48 & 0.13 & 2.35 & $2.46(1.68)$ & -0.11 \\
\hline Excitement-Seeking & $4.89(1$ & $4.30(1.99)$ & 0.59 & 2.84 & $3.13(1.84)$ & -0.29 \\
\hline Positive Emo & 5.29 & 4.84 & 0.45 & 2.51 & 2.7 & -0.22 \\
\hline \multicolumn{7}{|l|}{ Openness } \\
\hline Fantasy & 4.86 & 4.34 & 0.52 & 2.57 & 2.96 & -0.39 \\
\hline Aesthetics & $3.30(1$ & 2.68 & 0.62 & 3.95 & 3.94 & 0.01 \\
\hline Feelings & $4.32(1$ & 4.08 & 0.24 & & & .08 \\
\hline Actions & 5.48 & 4.82( & 0.66 & 3.02 & 3.35 & -0.33 \\
\hline Ideas & $4.90(1.82)$ & $4.44(1.86)$ & 0.46 & 2.88 & $3.48(1.70)$ & -0.60 \\
\hline Values & $4.99(1$. & $4.59(1.92)$ & 0.40 & 3.03( & 3.31 & -0.28 \\
\hline \multicolumn{7}{|l|}{ Agreeableness } \\
\hline Trust & 4.95 & 4.50 & 0.45 & 3.16 & 3.46 & -0.30 \\
\hline Straightfo & $5.87(1.65)$ & $5.00(1.93)$ & 0.87 & $3.06(1.79)$ & $3.54(1.89)$ & -0.48 \\
\hline Altruism & 4.31 & 4.06 & 0.25 & 3.07 & & -0.10 \\
\hline Compliance & $5.08(1$ & $4.41(2.00)$ & 0.67 & 3.03 & $3.52(1.91)$ & -0.49 \\
\hline Modesty & $4.68(2.08)$ & $4.12(2.09)$ & 0.56 & $3.52(1.92)$ & $3.84(1.83)$ & -0.32 \\
\hline Tender-mindednes & $4.62(1.96)$ & $4.35(1.93)$ & 0.27 & $3.21(1.87)$ & $3.44(1.86)$ & -0.23 \\
\hline \multicolumn{7}{|l|}{ Conscientiousness } \\
\hline Competence & $5.31(1.95)$ & $4.98(2.15)$ & 0.33 & $2.81(1.84)$ & $3.13(2.00)$ & -0.32 \\
\hline Order & $5.36(1.80)$ & $4.95(2.00)$ & 0.41 & 2.56 & $2.67(1.76)$ & -0.11 \\
\hline Dutifulness & $5.51(1.84)$ & $5.21(2.01)$ & 0.30 & $2.64(1.75)$ & $2.74(1.85)$ & -0.10 \\
\hline Achievement & $6.02(1.66)$ & $5.51(1.80)$ & 0.51 & $2.06(1.47)$ & $2.52(1.74)$ & -0.46 \\
\hline Self-Discipline & $5.22(1.89)$ & $4.82(2.00)$ & 0.40 & $2.69(1.69)$ & $2.96(1.80)$ & -0.27 \\
\hline Deliberation & $4.81(1.99)$ & $4.22(2.10)$ & 0.59 & $3.28(1.85)$ & $3.65(1.97)$ & -0.37 \\
\hline Average across all traits & $4.98(1.84)$ & $4.53(1.94)$ & 0.45 & $2.88(1.68)$ & $3.21(1.82)$ & -0.33 \\
\hline
\end{tabular}

Note. Chg $=$ Change in rating from before to after the election. 
Figure 1

Personality facet profile of Trump from Trump and Clinton voters

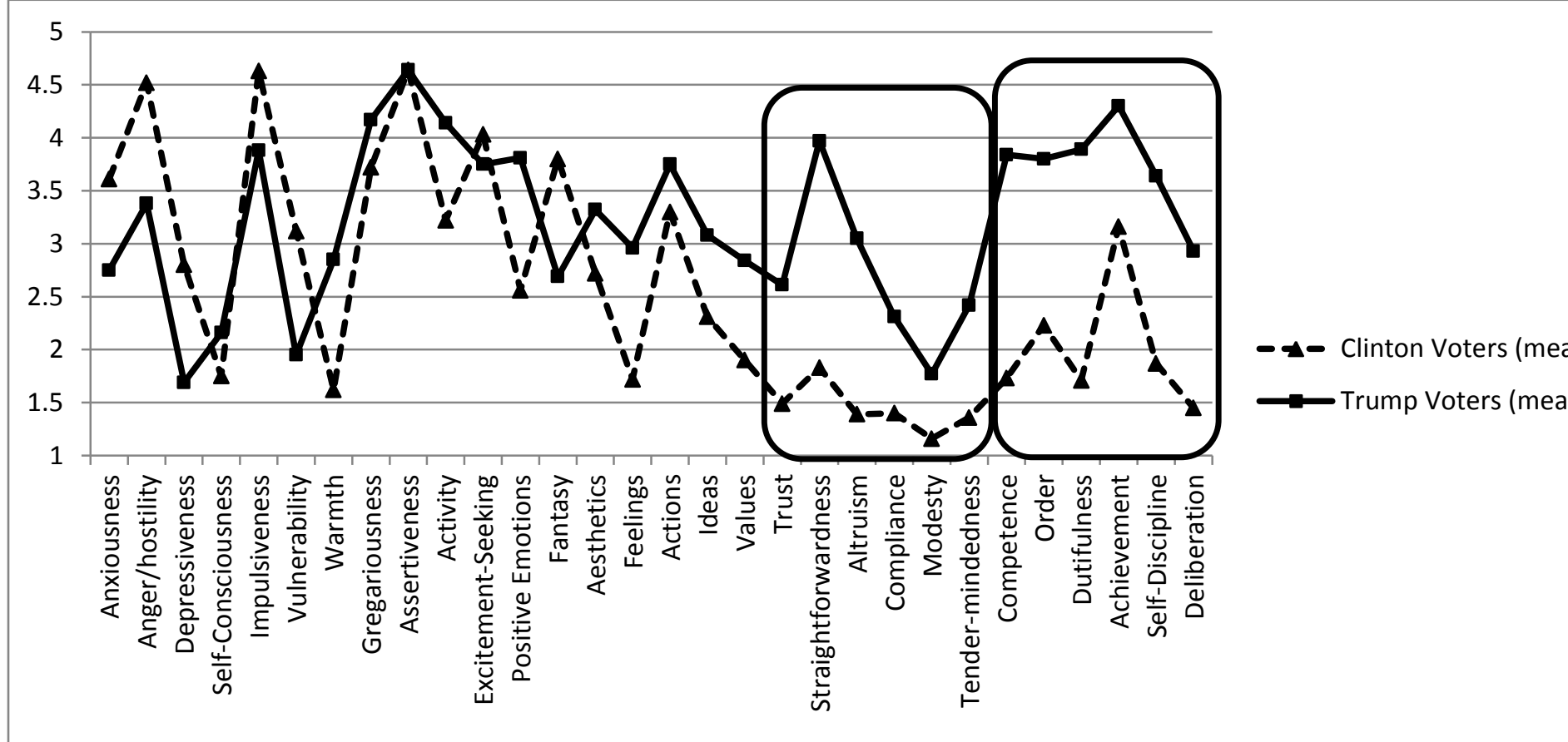

Note: The vertical axis ranges from $1=$ not at all to $7=v e r y$ much. The two boxes show areas of major disagreement with facets of agreeableness (left) and conscientiousness (right). 
Figure 2

Trump personality profile as matched to expert profiles

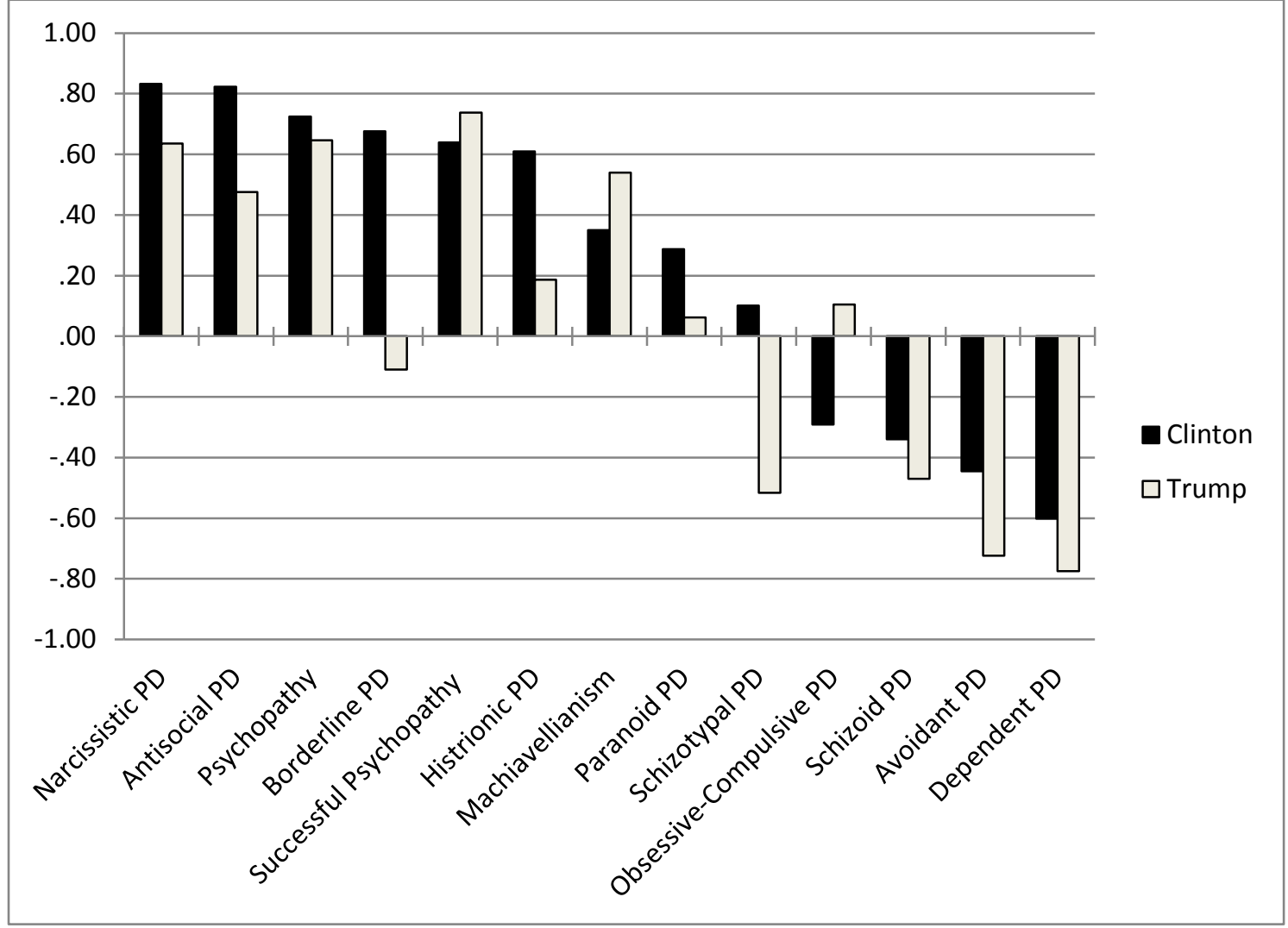

Note: Scores are correlations, with a high correlation indicating a similar pattern of FFM traits as seen in Trump also seen in expert profiles of trait/PD. 
Supplemental Table 1

Agreement Statistics for Current and Previous Expert Ratings

\begin{tabular}{|l|l|l|l|l|l|}
\hline Construct & $\mathrm{N}$ & $r_{\mathrm{WG}}$ & Interrater $r$ & $\mathrm{CITC}$ & alpha \\
\hline Clinton Voters & 120 & 0.38 & 0.47 & 0.74 & 0.99 \\
\hline Trump Voters & 117 & 0.35 & 0.33 & 0.62 & 0.99 \\
\hline
\end{tabular}

Note: $\mathrm{N}$ represents the number of raters involved; $r_{\mathrm{WG}}$ is the average, across all thirty facets of the FFM, proportional reduction in error variance relative to a uniform distribution. Interrater $r$ is the average correlation among all ratings in which raters are treated as variables and FFM facets are treated as cases. CITC is the average corrected item-total correlation (i.e., correlation between a given rater profile and the average of the remaining rater profiles). Alpha is the coefficient alpha is the alpha for the composite in which raters are treated as variables and FFM facets as cases. 
Supplemental Table 2

Agreement Statistics for Personality Facets.

\begin{tabular}{|l|c|c|}
\hline & \multicolumn{2}{|c|}{ Within-group rs for Facets } \\
\hline Facet & Clinton & Trump \\
\hline N1 & 0.20 & 0.28 \\
\hline N2 & $\mathbf{0 . 7 1}$ & $\mathbf{0 . 4 3}$ \\
\hline N3 & 0.27 & $\mathbf{0 . 5 0}$ \\
\hline N4 & 0.19 & 0.05 \\
\hline N5 & $\mathbf{0 . 6 4}$ & $\mathbf{0 . 3 9}$ \\
\hline N6 & 0.21 & $\mathbf{0 . 3 8}$ \\
\hline E1 & $\mathbf{0 . 5 6}$ & $\mathbf{0 . 4 1}$ \\
\hline E2 & $\mathbf{0 . 3 3}$ & $\mathbf{0 . 5 2}$ \\
\hline E3 & $\mathbf{0 . 6 7}$ & $\mathbf{0 . 7 7}$ \\
\hline E4 & 0.31 & $\mathbf{0 . 5 7}$ \\
\hline E5 & $\mathbf{0 . 3 9}$ & $\mathbf{0 . 5 7}$ \\
\hline E6 & 0.20 & $\mathbf{0 . 4 5}$ \\
\hline O1 & 0.09 & 0.05 \\
\hline O2 & 0.01 & 0.25 \\
\hline O3 & $\mathbf{0 . 5 0}$ & 0.20 \\
\hline O4 & -0.21 & 0.34 \\
\hline O5 & 0.07 & $\mathbf{0 . 3 5}$ \\
\hline O6 & 0.27 & 0.29 \\
\hline A1 & $\mathbf{0 . 6 0}$ & $\mathbf{0 . 4 1}$ \\
\hline A2 & 0.18 & 0.19 \\
\hline A3 & $\mathbf{0 . 6 3}$ & 0.22 \\
\hline A4 & $\mathbf{0 . 6 9}$ & $\mathbf{0 . 4 3}$ \\
\hline A5 & $\mathbf{0 . 8 6}$ & $\mathbf{0 . 3 9}$ \\
\hline A6 & $\mathbf{0 . 7 3}$ & $\mathbf{0 . 4 3}$ \\
\hline C1 & $\mathbf{0 . 5 0}$ & 0.26 \\
\hline C2 & 0.28 & 0.30 \\
\hline C3 & $\mathbf{0 . 3 8}$ & 0.33 \\
\hline C4 & 0.01 & 0.35 \\
\hline C5 & $\mathbf{0 . 3 8}$ & 0.27 \\
\hline C6 & $\mathbf{0 . 6 1}$ & 0.08 \\
\hline No & . \\
\hline
\end{tabular}

Note: Numbers in table represent within-group $r$; more specifically, they represent the proportion of reduction in error variance relative to a uniform distribution in which each response category is equally represented. All $r_{\mathrm{wg}}$ greater than or equal to 0.35 are bolded. 
Supplemental Table 3A.

Ratings of Trait-Related Helpfulness/Harmfulness by Clinton Voters, Means and (Standard Deviations)

\begin{tabular}{|l|l|l|}
\hline Trait & Help Personal & Harm Personal \\
\hline Anxiousness & $3.48(1.81)$ & $3.45(1.81)$ \\
\hline Anger/hostility & $2.89(1.65)$ & $4.16(1.80)$ \\
\hline Depressiveness & $3.22(1.91)$ & $2.83(1.79)$ \\
\hline Self-Consciousness & $3.53(1.94)$ & $3.59(1.78)$ \\
\hline Impulsiveness & $3.32(1.80)$ & $3.94(1.67)$ \\
\hline Vulnerability & $3.21(1.72)$ & $3.39(1.78)$ \\
\hline Warmth & $2.81(1.74)$ & $3.77(1.16)$ \\
\hline Gregariousness & $4.30(1.86)$ & $3.27(1.59)$ \\
\hline Assertiveness & $4.06(1.89)$ & $3.45(1.68)$ \\
\hline Activity & $3.65(1.76)$ & $2.87(1.49)$ \\
\hline Excitement-Seeking & $3.59(1.74)$ & $3.10(1.65)$ \\
\hline Positive Emotions & $3.46(1.72)$ & $3.46(1.64)$ \\
\hline Fantasy & $3.33(1.74)$ & $3.29(1.77)$ \\
\hline Aesthetics & $3.24(1.78)$ & $3.01(1.70)$ \\
\hline Feelings & $2.95(1.79)$ & $3.99(1.82)$ \\
\hline Actions & $3.43(1.74)$ & $3.56(1.84)$ \\
\hline Ideas & $3.10(1.64)$ & $3.32(1.69)$ \\
\hline Values & $3.37(1.79)$ & $3.48(1.72)$ \\
\hline Trust & $2.99(1.82)$ & $3.97(1.94)$ \\
\hline Straightforwardness & $3.25(2.01)$ & $4.00(1.82)$ \\
\hline Altruism & $3.11(2.03)$ & $3.51(1.80)$ \\
\hline Compliance & $3.20(1.88)$ & $3.64(1.80)$ \\
\hline Modesty & $3.39(1.88)$ & $3.50(1.76)$ \\
\hline Tender-mindedness & $2.93(1.63)$ & $3.70(1.73)$ \\
\hline Competence & $3.08(1.97)$ & $3.44(1.91)$ \\
\hline Order & $2.99(1.83)$ & $2.89(1.67)$ \\
\hline Dutifulness & $3.29(1.94)$ & $3.44(1.80)$ \\
\hline Achievement & $4.05(2.00)$ & $2.88(1.68)$ \\
\hline Self-Discipline & $3.04(1.78)$ & $3.50(1.86)$ \\
\hline Deliberation & $3.02(1.71)$ & $3.72(1.71)$ \\
\hline Average across all traits & $\mathbf{3 . 3 1}$ & $\mathbf{3 . 4 7}$ \\
\hline & & \\
\hline
\end{tabular}


Supplemental Table 3B.

Ratings of Trait-Related Helpfulness/Harmfulness by Trump Voters

\begin{tabular}{|c|c|c|}
\hline Trait & Help Personal & Harm Personal \\
\hline Anxiousness & $4.29(1.99)$ & $2.66(1.67)$ \\
\hline Anger/hostility & $3.64(1.89)$ & $3.20(1.82)$ \\
\hline Depressiveness & $4.40(2.22)$ & $2.18(1.38)$ \\
\hline Self-Consciousness & $4.39(2.00)$ & $2.81(1.69)$ \\
\hline Impulsiveness & $3.91(1.80)$ & $3.25(1.74)$ \\
\hline Vulnerability & $4.44(1.97)$ & $2.51(1.67)$ \\
\hline Warmth & $4.06(2.07)$ & $3.19(1.90)$ \\
\hline Gregariousness & $4.58(2.07)$ & $2.81(1.73)$ \\
\hline Assertiveness & $4.98(1.91)$ & $2.77(1.64)$ \\
\hline Activity & $5.23(1.80)$ & $2.29(1.45)$ \\
\hline Excitement-Seeking & $4.25(1.98)$ & $2.74(1.73)$ \\
\hline Positive Emotions & $4.72(1.85)$ & $2.71(1.71)$ \\
\hline Fantasy & $4.18(2.00)$ & $2.53(1.71)$ \\
\hline Aesthetics & $2.62(1.69)$ & $3.96(1.96)$ \\
\hline Feelings & $3.87(1.97)$ & $3.19(1.84)$ \\
\hline Actions & $4.68(1.85)$ & $2.66(1.56)$ \\
\hline Ideas & $4.14(1.88)$ & $2.82(1.73)$ \\
\hline Values & $4.26(1.96)$ & $2.72(1.62)$ \\
\hline Trust & $4.27(1.96)$ & $3.07(1.74)$ \\
\hline Straightforwardness & $4.88(1.95)$ & $2.84(1.57)$ \\
\hline Altruism & $4.29(2.05)$ & $2.74(1.82)$ \\
\hline Compliance & $4.19(1.94)$ & $2.82(1.63)$ \\
\hline Modesty & $4.28(1.97)$ & $3.20(1.82)$ \\
\hline Tender-mindedness & $4.07(2.00)$ & $3.10(1.88)$ \\
\hline Competence & $5.11(1.93)$ & $2.51(1.54)$ \\
\hline Order & $4.72(1.88)$ & $2.46(1.48)$ \\
\hline Dutifulness & $4.90(2.02)$ & $2.44(1.60)$ \\
\hline Achievement & $5.14(1.95)$ & $2.73(1.77)$ \\
\hline Self-Discipline & $4.80(1.87)$ & $2.69(1.60)$ \\
\hline Deliberation & $4.20(1.93)$ & $2.89(1.72)$ \\
\hline Average across all traits & 4.38 & 2.81 \\
\hline
\end{tabular}

